\title{
THE NATURE OF COAL
}

A SYMPOSIUM on the nature of coal was held at the Central Fuel Research Institute, Bihar, during February 7-9. The delegates were welcomed by Dr. A. Lahiri, director of the Institute, and by Prof. M. S. Thacker, director-general of scientific and industrial research in India, who referred to the valuable work already done by the Institute and to the need for symposia to review progress and exchange ideas. Dr. B. C. Guha of University College, Calcutta, gave the inaugural address. Coal, he said, was the parent of the industrial revolution and our principal source of heat and power. With the advent of atomic energy, some people feel that the use of coal as a fuel will decrease. Even if this were true, however, coal will still remain the source of numerous organic compounds-dyes, drugs, plastics and explosives. After less than a century of research on coal there remains much to be learnt and, no doubt, many new materials and processes to be developed.

The main subjects of the symposium were the origin and formation of coal ; petrographic studies ; $X$-ray structure; the constitution of coal as revealed by physical methods or by chemical methods; and the physico-chemical properties of coal. Contributions were received from a number of foreign countries, including Great Britain, the U.S.S.R., Japan, the United States, Canada, Australia, New Zealand, Czechoslovakia, Belgium, and West Germany.

In the session dealing with the origin and systematies of coal, the opening paper, by Dr. A. Lahiri, was on the metamorphism of coal, that is to say, on the transformation of vegetable matter and peat to lignite, bituminous coal and anthracite. This is referred to again later. In addition, there were interesting contributions from certain Russian investigators, namely, W. Rakovsky on the processes of formation of fuels and ways of solving the general problem of genesis, N. M. Karavayev on the early stages of formation of fossil fuel, A. Z. Yurovsky on the theory of the origin of sulphur in coals, V. S. Veselovsky on the chemical nature of caustobioliths from the point of view of genesis, and V. I. Kassatochkin on the physico-chemical aspects of the metamorphism of coals. There was also a welldiscussed paper by A. Gillet and P. Colson on petroleum and anthracite from cellulose. Prof. Gillet, in presenting this paper, first dealt with the earlier work on the subject and later expounded his theories of the development of the main liquid and solid fuels from cellulose, employing numerous diagrams for illustration.

In the following session, papers were presented on petrographic studies on Indian coals and their relation to certain chemical properties, the significance of X-ray studies in the elucidation of problems of coal formation, deductions from recent $\mathrm{X}$-ray data on coals, X-ray studies on oxidized coals and humic acids. On the ultra-fine structure of coal, the contributions were made on the sorption properties and structure, on the relation between internal surface and functional group measurements, on the adsorption of kxypton by coal, and on the porosity of coal and of carbonized products as revealed by densities using helium and mercury as the displaced liquid. Considerable interest was shown in 'heat of wetting' and in the significance of the results obtained by different methods of determination.

In the papers and discussions on physical methods of studying the constitution of coals, the nine steps of Seyler did not receive support from T. N. Basu and D. Bagchi in their work on reflectance. Definite changes of reflectance, however, were confirmed at 85 per cent carbon and at 90-91 per cent carbon. Indeed, the changes when the carbon of coal exceeds 85 per cent were noted by many contributors from different sources. These changes are reflected in natural moisture, density, calorific value, oxygen, and coking properties, and seem to be related broadly to the elimination of hydroxyl groups in a drastic and abrupt manner involving re-orientation of molecular structure, probably with formation of quinone linkages. In India the mine dusts from such coals (85 per cent carbon) seem particularly dangerous in respect of mine explosions.

J. D. Brooks (Australia) presented a useful review of the principal chemical methods of investigating the constitution of coals, covering the results obtained by the various methods of determining functional groups, oxidation reactions, hydrogenation, hydrogenolysis, sulphonation, hydrolysis and pyxolysis of coals. J. B. Stott (New Zealand) dealt with the effects of evaporation on the early stage of spontaneous combustion of coal. Problems of coal heating have often presented baffling inconsistencies in the past : many of these could probably be explained by the influence of evaporation of water.

L. D. Ahuja and others, in discussing the conversion of non-coking coal to coking coal by partial hydrogenation, considered that the improvement in coking property is largely bound up with the removal of the more stable oxygen linkages. Drs. P. N. Mukherjee and A. Lahiri, dealing with the constitution of humic acids, pointed out that, on the basis of X-ray and infra-red studies, there is a close similarity between the structural units of coal and humic acids. From studies of various properties, including ultimate composition, molecular weight, equivalent weight and the distribution of functional groups, a tentative structural model was suggested for humic acids.

M. S. Iyengar and others claimed that with highsulphur coals (up to 6 per cent organic sulphur) there are three different types of sulphur, namely : (1) sulphur eliminated during the initial stages of oxidation; (2) sulphur oxidized to sulphonic acids ; and (3) sulphur resistant to oxidation. The first type has not been identified, the second has been identified as thiophenol, while the third is tentativoly assumed to be thiophene.

A striking paper was given by B. K. Mazumdar and his colleagues on dehydrogenation studies carried out on several coals of different rank, on vitrains, on oxidized and weathered coals, and on coal extracts and pitch. They had used Vesterberg's technique. The optimum temperature for dehydrogenation with sulphur was found to be $200^{\circ}-360^{\circ} \mathrm{C}$. for bituminous coals and lignites. (Anthracite reacts with sulphur only above $480^{\circ} \mathrm{C}$.) The hydrogen sulphide evolved accounts for more than 92 per cent of the products of reaction, but small amounts of methane are also detected. Dehydrogenation under these 
conditions was ascribed primarily to the presence of alicyclic (hydro aromatic) structures, and the amount present was measured by the hydrogen sulphide formed. This was confirmed by a hydrogen balance of the coal and its dehydrogenated products. It was shown that 'alicyclicity' progressively diminished with rank, from 25 per cent in lignite to almost nil in anthracite. Similarly, alicyclicity with respect to hydrogen $(\mathrm{Hal} / \mathrm{H})$ varied from 60 per cent in lignite to nil in anthracite.

Further dehydrogenation of coal resulted in complete destruction of coking properties, inhibition of the formation of tar, and higher yields of charapparently at the expense of the tar bodies. The yield of low-temperature tar was found to be proportional to (and also nearly equal to) the alicyclic carbon in coal.

Prior dehydrogenation led to the retention of 90 per cent of the original carbon of coal in lowtemperature carbonization char, whether employing lignites or bituminous coals, whereas in normal (high-temperature) carbonization only 70-80 per cent of the carbon of the same coals was retained. The 'extra' carbon retained as a result of dehydrogenation and subsequent pyrolysis was considered to be a measure of the alicyclic carbon and hence of alicyclic hydrogen. A simple test of volatile matter in the presence of sulphur or selenium would afford a direct estimate of the alicyclic carbon retained in the char.

B. K. Mazumdar and his colleagues also explained the influence of the alicyclic component on the behaviour of coal in coking and tar formation, spontaneous combustion and weathering. Knowledge of the alicyclicity of coal enabled one to compute the aliphaticity, which was practically constant for all coals at 9-10 per cent of the carbon.

In a paper on aliphatic hydrogen in coal, J. N. Bhowmick and his collaborators described experiments employing chlorination to determine the aliphatic groups. Exhaustive chlorination of the coal at $200^{\circ} \mathrm{C}$. was followed by hydrolysis in potassium hydroxide solution, and on the basis of the estimation of the functional groups formed in the hydrolysed products, as well as the loss of carbon sustained during chlorination, the distribution of aliphatic groups in coals of different ranks was worked out.

F. Kaiser, H. S. Rao and A. Lahiri, reporting on the disposition of methyl groups, described work in which they first formed an estimate of the side-chains in coal by the application of Kuhn-Roth's procedure for the determination of $\mathrm{C}-\mathrm{CH}_{3}$ groups. (The method depends on the fact that every side-chain contains one, and only one, methyl group, and that every methyl group can exist only as the terminal carbon of a side-chain.) The variation of $\mathrm{C}-\mathrm{CH}_{3}$ content with increase in rank was studied, and a free radical mechanism postulated for the coalification process. The mechanism attempts to explain two important facts associated with the metamorphism of coal, namely, the increase in aromaticity and the evolution of methane during the coalification process.

Dealing with pyrolysis and its relation to the structural parameters of coal, B. K. Mazumdar, S. K. Chakrabartty and A. Lahiri showed how, on a basis of recent knowledge obtained from $\mathrm{X}$-ray and infra-red studies on carbonized coal (and in the light of oxidation and dehydrogenation studies on coal and its carbonized products), a mechanism could be worked out for the pyrolysis of coal up to $600^{\circ} \mathrm{C}$. Low-temperature $\left(600^{\circ} \mathrm{C}\right.$.) coke or char, they claimed, is entirely aromatic in character and no aromatic carbon of coal is lost by carbonization at $600^{\circ} \mathrm{C}$. The primary bodies of tar come mainly from the alicyclic component, whereas the hydrocarbon gases come from the aliphatic structures. Correlation was shown to exist between the yield of gas and aliphaticity.

N. Berkowitz, in dealing with the decomposition and diffusion processes in coal pyrolysis, claimed that the classical interpretation attached to the weight-loss temperature curve (namely, that it indicates a slow and extended chemical decomposition) is at variance with experimental facts. Such curves, if interpreted in the light of a diffusion process, offer material from which several important conclusions about the nature and kinetics of the pyrolytic processes can be drawn.

The broad picture that emerged from the papers and discussions was that coal can be regarded as essentially a binary mixture of aromatics dispersed in non-aromatics via carboxyl groups. Fusain (long attributed to forest fires) was probably one of the primary stages in coal formation.

Summarizing and following Lahiri on the metamorphism of coal, the general trend in the changes from peat to lignite, and bituminous coals, is primarily one of dehydration. At certain stages this dehydration seems to occur in discrete steps, notably at about 70,85 and 91 per cent carbon. With increasing enrichment in carbon there is a diminution in the water-holding capacity of the material, representing a change from 'sol' to 'gel'. At the lignite stage there occurs an increase in hydroxyl groups. both alcoholic and phenolic, with some carboxyl groups, but quinone and carbonyl groups are relatively scarce. Some of the coal carbon-about 20 per cent -is present as alieyclic compounds, but about 60 per cent is in the form of aromatic compounds. This complex colloidal gel in lignite is still dispersed in water. The dispersing phase (water) is not merely absorbed physically in pores or micropores, but is largely held to the organic mass by chemisorption or hydrogen bonding and polar absorption. When the moisture falls to 15 per cent or so, the sub-bituminous or ligno-bituminous stage is reached, but the alicyclicity and aromaticity are largely unaffected. The oxygen and moisture in the dispersed phase are reduced, largely through dehydroxylation and decarboxylation, but dehydroxylation still continues up to 84-85 per cent carbon. Here, however, there is a marked change in capacity moisture and coking properties, reflected in changes of hardness, elasticity, calorific value and resistance to weathering. The reflectance and refractive index are also increased. alicyclic carbon increases, and also the yield of tar. Thus, the sol-to-gel transformation is complete and the stage of true bituminous coking coals reached. Under X-ray diffraction the structure of the coal showed an apparent emergence of order from previous disorder, but there is no definite evidence of any appreciable increase in the number of rings (averaging 4 or 5) : the aromatic nucleus does not grow, although the coal becomes predominantly aromatic. Alicyclic carbon falls to 10 per cent of the coal, but is of great value in providing the 'coking constituents' of Bone and Fischer. Coking coals consist of aromatic ring structures dispersed in alicyclic carbon structures. In Nature such changes are apparently brought about by high tectonic pressures with considerable evolution of methane, especially when the carbon rises from 85 to 87 per cent.

Finally, in anthracites, the 'ordered' carbon is involved : there is an abrupt rise in reflectance and in aromaticity, with changes in general appearance 
including the elimination of banding and petrographic heterogeneity. Coking properties are destroyed, and there is a small but definite rise in moisture content. The hydrogen content falls by 25-50 per cent of its earlier value. Apparently the organic gel has been transformed into an organic crystalloid. The process is thus primarily dehydration followed by decarboxylation, dehydroxylation and demethylation. The original aromatic carbon groups are not much affected by geochemical and geological changes until the 91 per cent carbon rank is reached. It is the variations in the alicyclic and aliphatic bodies which are largely responsible for the different types of coal, especially of bituminous coal.

The proceedings of the symposium are to be pub. lished in book-form.
J. W. Whitaker

\title{
ROLE OF POLY- $\beta$-HYDROXYBUTYRIC ACID IN THE ASSIMILATION OF ORGANIC CARBON BY BACTERIA
}

\author{
By Prof. M. DOUDOROFF and Prof. R. Y. STANIER \\ Department of Bacteriology and Miller Institute, University of California, Berkeley
}

\begin{abstract}
N 1936, Barker ${ }^{1}$ observed that resting cells of a colourless alga, Prototheca zopfii, assimilate a large fraction of the carbon of the organic substrates which they oxidize. The same phenomenon was soon shown to occur in bacteria, 2,3 , and for some years the study of 'oxidative assimilation' had a considerable vogue among bacterial physiologists. The relevant literature has been reviewed by Clifton ${ }^{4}$. The discovery of the nature of bacterial photosynthesis by van $\mathrm{Niel}^{5}$ in 1931 was followed by studies on the photosynthetic metabolism of organic substrates by the purple bacteria, which showed that under anaerobic conditions in the light these organisms can perform a very effective assimilation of organic carbon ${ }^{6-8}$.

The work which has been done on the oxidative and photosynthetic assimilation of organic compounds by bacteria has thrown little light on the mechanism of the process. A dependence on the simultaneous formation of adenosine triphosphate is indicated by the observation that uncouplers of oxidative phosphorylation such as 2,4-dinitrophenol may prevent oxidative assimilation at levels which do not diminish the rate of respiration. From a study of the oxidative metabolism of specifically labelled radioactive substrates by Pseudomonas saccharophila, Wiame and Doudoroff ${ }^{9}$ concluded that acetyl frag. ments are the intracellular metabolites that undergo assimilation.
\end{abstract}

It is furthermore evident that assimilation is not necessarily coupled with general cellular synthesis and growth, since bacteria can assimilate organic carbon with unimpaired efficiency in the absence of a nitrogen source. Under these conditions, the flow of carbon into the nitrogenous constituents of the cell must be negligible, and it could therefore be expected that the assimilated carbon accumulates in a limited group of cell materials. The evidence on this question is scanty and not clear. Gaffron, who first studied the photosynthetic assimilation of organic compounds by resting cells of purple bacteria, ${ }^{6,7}$, postulated the existence of a primary assimilatory product with the empirical formula $\left(\mathrm{C}_{4} \mathrm{H}_{6} \mathrm{O}_{2}\right)_{n}$, and succeeded in isolating small quantities of a polymerie substance with this elementary composition from cultures grown photosynthetically on butyrate. Further pursuit of this lead seems to have been discouraged by van Niel's report ${ }^{10}$ that the gross composition of the cells of purple bacteria corresponds closely to the composition of Gaffron's postulated assimilatory product, and the problem has remained where Gaffron left it in 1935 . Inconclusive results have been obtained in the search for products of oxidative assimilation by resting bacteria. Wiame and Doudoroff ${ }^{9}$ were unable to identify the radioactive cell-constituents formed by Pseudomonas saccharo. phila at the expense of substrates labelled with carbon-14, and suggested tentatively that the assimilated carbon flowed into many different cell materials, including proteins. Recently a similar conclusion was reached by Morita ${ }^{11}$, who studied the dark oxidative assimilation of acetate, labelled with carbon-14, by Rhodopseudomonas palustris.

In 1927, Lemoigne ${ }^{12}$ discovered that a polvester of $\beta$-hydroxybutyric acid is a major component of the cells of Bacillus megaterium, and the same substance was later found in other Bacillus species ${ }^{13}$. There is a considerable literature on the properties and metabolic behaviour of poly- $\beta$-hydroxybutyric acid in the genus Bacillus ${ }^{12-20}$, and the accumulated evidence suggests that it functions as an intracellular reserve of carbon and energy for these bacteria. The recent observations of Macrae and Wilkinson ${ }^{20}$ provide particularly convincing support for this hypothesis. The possible relevance of the investigations on poly- $\beta$ hydroxybutyric acid to the more general problem of bacterial oxidative and photosynthetic assimilation has been overlooked, no doubt because this polymer appeared until recently to be confined to a few species of bacteria. It was found in Azotobacter many years ago $^{21}$; but its widespread occurrence in Gramnegative bacteria was first demonstrated in $1958^{22}$. It has not been detected in any other group of microorganisms, or in higher plants and animals.

The observation by our colleague Dr. Germaine Cohen-Bazire that purple bacteria accumulate massive quantities of poly- $\beta$-hydroxybutyric acid during photosynthetic growth on eertain organic substrates prompted us to investigate its role in bacterial assimilation. We have examined the products of oxidative assimilation from glucose, acetate and butyrate in Pseudomonas saccharophila, and of photosynthetic assimilation from acetate and butyrate in Rhodospirillum rubrum. In all cases, a major fraction of the assimilated carbon (60-90 per cent) initially accumulates within the cell as poly- $\beta$ hydroxybutyric acid; when the external substrate is removed, there is a fairly rapid intracellular breakdown of the stored polymer. These observations suggest that poly- $\beta$-hydroxybutyric acid may have a general physiological function in bacteria as a primary product of carbon assimilation, its role in bacterial metabolism being analogous to that of 